\title{
Editorial
}

\section{Integration Trends in the 90s}

Project 'Europe 1992' is striving for unimpeded movement of goods, services, people and capital over a single market of 320 million people. European technical standards will now have to replàce the national ones. Ultimately, global standards will have to replace the European ones. No nation and no business should impose or dictate its own standards on the others.

The form of these standards will be crucial also to U.S. business and social interests. As an example, while remaining on the obsolete nonmetric system, it is hard to imagine how the U.S. can even start forming viable competitive strategies in terms of customized product quality, product individualization, reliability, user self-maintainability, selfrepair and self-service of its export products.

Quality standards of any one nation do not have to be acceptable to any other nation. Internally, a nation can produce as much 'junk', artificial preservatives, deceptive advertising and hormones-ridden meat as its own consumers would allow. But exporting or sharing within an integrated system is a different matter. 'Our customer-our master' must ring true even if our customer happens to be poor, far away or perhaps 'too finicky' or yellow.

Nobody should be forced to eat expensive and substandard rice when the world is ready to deliver much better and cheaper rice. Nobody should accept expensive and unreliable automobiles, when cheaper and better alternatives are available. Each country must be free to judge the desirability of 'little boys with sagging breasts' even though a hormone-based culture might be perfectly happy with them. Nobody should be forced to drink perfumes and paint thinners while fine wines and beers are enjoyed by others. This World is for sharing 'the best', not the worst.

IOS

Human Systems Management 8 (1989) 91-93
American entrepreneurial abandonment of China to Japan, and emerging virtual abandonment of USSR to Western Europe, appear to be failures of monumental proportions. Among the medieval cries of 'protectionism' and 'they have to buy our stuff', we are missing just about all the boats leading towards to global integration.

Although one can see the logic and desirability of setting minimum quality standards for integrated entities, what about interfering with the standards of 'outsider' nations? Does a country have a moral right to supply its population with substandard or harmful goods, when cheaper and higherquality alternatives might be readily available elsewhere?

Quality of products, goods and services, their integrity, wholesomeness and purity, these will be among the new 'human rights' in the nineties. It is the human right of each citizen of this Earth to strive for enjoying the freedoms which others, the more fortunate ones, already enjoy. That's what the fight for human rights is all about.

It is an equally human right to enjoy the quality, reliability and purity of products, services and environment which others, the more fortunate ones, already enjoy. This 'fight' will be much more difficult and perhaps has not been started yet. But, it is equally important.

That is why we need standards. To know what is 'the very best', what is the 'world-class', what is the 'world bench-mark' of today. Competitive benchmarking has to involve the entire world, not just a local market or region. Globalization has a significant effect on new human rights: the rights to a good product according to world standards.

That is why standards are needed.

Can a country consume 'junk' if its consumers so choose in an open, unprotected and free international market? Sure. But others may want the best 
there is and are willing to work and pay for it. They have their rights too.

The nineties will be a decade of 'business ecology'

European International Symposium on Information Technology (IT) Standardization (INSITS) has taken place in Braunschweig (West Germany) in July 4-7, 1989. The process of IT standardization was explored in the context of its broad economic, political and technological embeddings, not only in terms of specific families of technical standards. Product-oriented standardization was understandably one of the major topics. Standards have to relate to quality, immediate useability, competitiveness, flexibility and design-continuity of products, not to union representation, number of coffee breaks and technology curtailment of the bureaucrats. How to divorce standardization from bureaucratization will be one of the major challenges for Europe of 1990s.

Setting the standards cannot be separated from quality management systems and requisite professional activities in which they are to function. So it is also the meta-standards of quality assurance, testing and certification which require similarly prominent attention.

Specifically, concerns of information technology (IT) standardization include definition, achievement and improvement of 'high' quality; conformance and legal issues; evaluation procedures; publicity, marketing and promotion of standards; issues of drafting, dissemination, balloting and approval; political and social impacts of standardization; voluntary and binding standards; and many other issues.

It is now becoming self-evident that the wave of integration is sweeping through the 'capitalistic' West, while the pre-integrative 'disintegration' or 'disunion' is accelerating in the 'socialistic' East. Only free, autonomous, uncoerced and economically self-confident entities can 'integrate'; all the rest can only 'be integrated' by decree from the top and that - as the failure of the so called COMECON (Council for Mutual Economic Cooperation) of Eastern Europe testifies - represents a dangerously ineffective anchronism.

The East European 'disunion' is only a temperary process, necessary for restoring the lost equality, autonomy and self-control of even potentially integra- ble entities. At the same time, and in harmony with this necessary 'disintegration', integrative tendencies are beginning to assert themselves with increasing vigor.

First, there is the Austro-Hungarian project of '1995', a joint hosting of the World Fair 'Expo '95'. Part of the plan is for Budapest and Vienna to become 'twin cities, connected by a newly built superhighway. More importantly, economic, cultural and even political integrations of the two (and neighboring) nations are bound to be initiated.

Then there is the revival of the idea of Central Europe ('Mitteleuropa'): a string of neutral (some of them already 'finlandized') nations and their economies, like Finland, Estonia, Lithuania, Latvia, Poland, Czechoslovakia, Austria, Hungary, Ukraine, Moldavia, Romania, Bulgaria, Yugoslavia, and Albania, closely cooperating with Switzerland and Lichtenstein, ultimately connecting with the united and neutral Germany. This vast, integrated Central Europe could become the best assurance for the USSR's security and economic well-being as well as the most desirable partner for the Integrated Common Market of the West. The string of countries has an unmatched opportunity and potential to 'leapfrog' directly into the rapidly emerging knowledge-based or knowledge-oriented economies and societies.

Similarly in the East, strong economic and cultural integrating forces are already pulling together Japan, China and the 'Five Dragons' (Taiwan, South Korea, Thailand, Singapore and Hong Kong). Together with Australia, New Zealand and the Phillippines, after some additional economically-lagging countries of the region become free, this Integrated Pacific Asia could become the most formidable economic power on Earth.

Another powerful, but regressive and counteracting integration, is also taking place, relying more on religion and ideology, than on knowledge, entrepreneurship and democracy: Iran, Afghanistan, Pakistan, India, Iraq, Azerbaidzhan, Arab States and North African States. This integration is also quite inevitable, especially vis-à-vis the West European, Pacific Asian and Central European trends.

We have identified three major regions of socioeconomic integration and at least one region of ideological-religious integration in the world of the 
nineties. Vast areas of South America and Africa, as well as USSR and USA, still remain outside these major integrative forces. The two super-powers are going to become increasingly isolated in the world of the nineties, declining in their influence and impact, ultimately being forced to choose: either adjoining themselves with one of the other of four integrative forces mentioned above, or interconnecting their own fates in a still 'incredible' but increasingly possible USA-USSR integration.

The invidivual integrated markets, with the exception of the ideological-religious ones and both super-powers, will find it increasingly more and more advantageous to foster their economic cooperation rather than competition, opening rather than protecting their markets, and allowing freer movement of people, information and goods.

For example, Central European and West European integrations would mutually benefit from some form of 'meta-integration', which would further enhance possible integration with the Asian-Pacific region. This is a possible scenario by which the so called globalization, or in our preferred vocabulary: business or economic ecosystem, is likely to emerge.

Integrated-World Economy (I-WE) is not to be brought about by multinational corporations, international investments and exports-imports presence only. It is continually being created and recreated by the ever-widening layers of freedom, starting from the individual, extending to groups and corporations, encompassing nations and states, and ultimately reaching large geographical portions of this Earth.

The opposite 'progression', i.e., starting at the state-nation-bloc level and reaching down to the individual, is an undesirable, ineffective and socio-economically anomalous remnant of the past era.

Global integration therefore starts with creating the conditions for free and autonomous individuals: individual is the key to globalization. The transition from ' $\mathrm{I}$ ' to ' $\mathrm{We}$ ' is natural and self-enhancing, while the reverse (as the failures of socialism indicate) is hardly possible: in fact, the reverse path from ' $W e$ ' to the ' $I$ ' has not been traversed as yet.

Increasingly, individual autonomy is becoming more important than individual freedom. Individuals can be fully and even dizzyingly free, yet remain far from being autonomous. Let us quote Adam
Smith (1776) on this issues:

The man whose whole life is spent in performing a few simple operations ... has no occasion to exert his understanding, or to exercise his invention ... He naturally loses, therefore, the habit of such exertion ... His dexterity at his own particular trade seems ... to be acquired at the expense of his intellectual virtues.

It is the 'most advanced' post-industrial societies of today, based on extreme specialization, hierarchical division of labor and management-workers separation, where the expert-worker dexterity translates into 'It ain't my job' syndrome and is being increasingly acquired 'at the expense of his intellectual virtues.

There is now an overwhelming evidence that factory and service employment, organized and based upon long-term carrying out of narrow and routine orders, tasks and functions, extinguishes employees' (and nation's) ambition, initiative and purposeful direction towards life goals, i.e., autonomy.

All members of our society, even if constitutionally free and unhindered, can lead the rational, goaldirected lives of autonomous agents only if the detailed or hierarchical division of labor is eliminated by economically sound and voluntary integration of task, labor and knowledge.

The strength-gathering trend from the age of specialization to the era of integration represents the movement towards desirable autonomy of individuals, groups, and nations - and the planet Earth itself.

We argue that employee autonomy is at the very root of globalization. It is hindered by the traditional distinction between workers (doers, actors and executors of decisions and orders) and managers (decision makers, coordinators and planners). No democratic or parliamentary 'overlay' can solve the problem of autonomy if it preserves or even enhances this underlying distinction.

Only those corporations which continually reduce such distinction, perhaps to the point where it becomes irrelevant, are the true harbingers of globalization and the true and autonomous participants in the emerging era of integration.

Milan ZELENY

Graduate School of Business

Fordham University at Lincoln Center New York, NY 10023, U.S.A. 